\title{
Uusioersily
}

\section{An Experimental Comparison between Presuppositions and Indirect Scalar Implicatures}

Romoli, J. (Accepted/In press). An Experimental Comparison between Presuppositions and Indirect Scalar Implicatures. In F. schwarz (Ed.), experimental perspectives on presuppositions (pp. 215-240). Springer.

Link to publication record in Ulster University Research Portal

Published in:

experimental perspectives on presuppositions

Publication Status:

Accepted/In press: 03/10/2014

\section{Document Version}

Author Accepted version

\section{General rights}

Copyright for the publications made accessible via Ulster University's Research Portal is retained by the author(s) and / or other copyright owners and it is a condition of accessing these publications that users recognise and abide by the legal requirements associated with these rights.

\section{Take down policy}

The Research Portal is Ulster University's institutional repository that provides access to Ulster's research outputs. Every effort has been made to ensure that content in the Research Portal does not infringe any person's rights, or applicable UK laws. If you discover content in the Research Portal that you believe breaches copyright or violates any law, please contact pure-support@ulster.ac.uk. 


\title{
An Experimental Comparison between Presuppositions and Indirect Scalar Implicatures
}

\author{
Jacopo Romoli and Florian Schwarz
}

\begin{abstract}
We compare two aspects of meaning, namely the presupposition of stop in the scope of negation (John didn't stop going to the movies on Wednesday., $\hookrightarrow$ John used to go to the movies before Wednesday.) and scalar implicatures associated with strong scalar items under negation (John didn't always go to the movie last week. $\hookrightarrow$ John sometimes went to the movies last week.) ('Indirect Scalar Implicatures' (ISIs) Chierchia, 2004). Our results replicate the finding by Chemla and Bott (2013) that global presupposition interpretations are faster with a different methodology that avoids a potential confound of response bias. More surprisingly, ISIs are found to pattern with presuppositions in that responses reflecting an interpretation without an inference (corresponding to a 'literal' interpretation) are slower than ones based on the relevant inference, contrary to what has been found for direct scalar implicatures. These results are puzzling from the traditional perspective that ISIs are generated in the same way as direct implicatures. We explore two possible interpretations: first, strong scalar terms could receive a presuppositional analysis as well and presuppose that their domain is non-empty. Alternatively, we could group stop and ISIs together from another angle and see them as obligatory scalar implicatures, in contrast to the non-obligatory direct ones.
\end{abstract}

Jacopo Romoli

Department of Cognitive Science, ARC Centre of Excellence in Cognition and its Disorders (CCD), Australian Hearing Hub, Level 3, Macquarie University e-mail: jacopo . romoli@mq. edu. au

Florian Schwarz

Department of Linguistics, University of Pennsylvania, 619 Williams Hall, 255 S. 36th Street, Philadelphia, PA 19104, e-mail: florians@ling.upenn. edu 


\section{Introduction}

As participants of conversations, we draw a variety of inferences from the sentences we hear. Some of these inferences are thought to be associated directly with the linguistic forms uttered, others instead are considered to go beyond the basic or literal meanings of the sentences they arise from. For instance, from a sentence like (1a) we typically conclude that the information in (1b) is true. Analogously, from a sentence like (2a) we tend to infer that John used to show up late for class, (2b).

(1) a. John sometimes went to the movies.

b. $\hookrightarrow$ John didn't always go

(2) a. John didn't stop showing up late for class.

b. $\hookrightarrow$ John used to show up late for class

The type of inference in (1b) is generally called a 'scalar implicature', while that in (2b) is a instance of a 'presupposition. ${ }^{1}$ While it is controversial what the place of these inferences should be with respect to the semantics/pragmatics divide, they are not considered to be part of the 'literal' truth-conditional meaning of (1a) and (2a). The main reason for this is that while these inferences are typically drawn, there are cases in which they appear to be absent, as we will see below. ${ }^{2}$ Moreover, how these inferences should be derived is far from being a settled matter in the literature. On the contrary, many theories have been proposed, some of which very different from each other. What is most relevant for us in connection to (1b) and (2b), however, is that the majority of these theories agree that these inferences are different in kind. ${ }^{3}$

In the psycholinguistic literature, inferences such as (1a) have been extensively studied, in particular from the perspective of how these inferences are processed (Bott and Noveck 2004; Bott et al. 2012; Breheny et al. 2006; Huang and Snedeker 2009, Chemla and Bott under review). More recently, work has also been conducted on presuppositions (Chemla and Bott 2013; Schwarz 2007; Schwarz and Tiemann 2012, 2013). One of the main findings of these studies on the processing of inferences exemplified in (1b) and (2b) is that they appear to have very different processing profiles - a difference that nicely reflects the theoretical distinction standardly posited in the literature. In the case of scalar implicatures such as (1a), there is evidence that they are associated with a processing cost when compared to the corresponding literal meanings. In response times studies, in particular, the delay

\footnotetext{
${ }^{1}$ The literatures on both topics are vast, so let us just point to recent overviews for further background reading: for scalar implicatures, see Chierchia et al. 2012 and Geurts 2010 and references therein; for presuppositions, see Beaver and Geurts 2012 and references therein.

${ }^{2}$ Notice that, strictly speaking, this fact alone does not imply that these inferences could not be part of the literal meaning of one of the possible interpretations of (1a) and (2a), if the latter are considered ambiguous. In fact, some accounts of scalar implicatures and presuppositions do posit some form of ambiguity to account for the optionality just mentioned. As the issue is not relevant for our discussion, we will ignore it here. See Chierchia et al. 2012 for discussion.

${ }^{3}$ There are some exceptions, in particular Chemla 2009b and Romoli 2012, Romoli (to appear). We will come back to these alternative approaches in the discussion section below.
} 
associated with evaluating a sentence in a situation consistent with its scalar implicature has been consistently found to be longer than that of a situation inconsistent with the scalar implicature (but consistent with the sentence's literal meaning) (Bott and Noveck 2004 and much subsequent work). Similar results have been found with other methodologies (Breheny et al. 2006; Huang and Snedeker 2009; but see Grodner et al. 2010). In other words, there appears to be solid evidence in the literature that responding based on meanings enriched with scalar implicatures is more costly than responding based on literal meaning. While presuppositions have been studied much less than direct scalar implicatures, one common result of the studies conducted is that, unlike the case of scalar implicatures, verifying or deriving presuppositions is not more costly than verifying or deriving the corresponding literal meaning, on the contrary, it appears to be less costly. Chemla and Bott 2013, in particular, have found that sentence verification in contexts consistent with the sentence's presupposition was faster than in contexts inconsistent with it (i.e., in situations only consistent with the sentence's literal meaning).

Seeing the processing results for the two types of inferences in comparison, the effects seem to go in opposite directions. In short, we could characterize this as follows: while the presence of direct scalar implicatures appears to be more costly than their absence, for presuppositions it is their absence that appears more costly than their presence. Schematically, the two main results from the processing of scalar implicatures and that of presupposition are represented in (3). ${ }^{4}$

(3) a. Presence of direct scalar implicatures $>$ Absence of direct scalar implicatures

b. Presence of presuppositions $<$ Absence of presuppositions

The difference in processing between presuppositions provides a useful diagnostic for evaluating the nature of other inferences (i.e., evaluating whether they are more like presuppositions or more like scalar implicatures). This is because one can investigate the processing profile of an inference and check where it stands with respect to the distinction in (3) (i.e., presence-more-costly-than-absence vs. absencemore-costly-than-presence).

In the experiment reported below, this is precisely what we have done. We have investigated inferences exemplified by (4b), based on sentences such as (4a), against the background of the distinction in (3). Following Chierchia (2004), we will label these 'indirect scalar implicatures', in contrast to the previously considered cases, which we will call 'direct scalar implicatures.'

(4) a. John didn't always go to the movies.

b. $\hookrightarrow$ John sometimes went

\footnotetext{
${ }^{4}$ Where $A>B$ can be interpreted for now as $A$ is associated with a higher processing cost than $B$. For reaction times studies, which are the most relevant for us, $A>B$ should be interpreted more specifically as $A$ gives rise to a longer reaction time than $B$.
} 
To our best knowledge, the processing of indirect scalar implicatures has not been systematically investigated. ${ }^{5}$ However, this is an important gap to be filled as it could tell us much about the relationship between them and direct scalar implicatures, on the one hand, and presuppositions on the other. This is particularly relevant because the inference in (4b) is generally regarded to be a scalar implicature of the very same kind as (1b). Indeed, (1b) and (4b) appear to be very similar and symmetric - the assertion in (1a) is the inference in (4) and, vice versa, the assertion in (4a) is the inference that we derive from (1a). Descriptively speaking, direct scalar implicatures arise from weak scalar terms in upward entailing contexts, while indirect scalar implicatures emerge when strong scalar terms are embedded in downward entailing ones.

While there are many different theories of scalar implicatures, what is important for us here is that essentially all of them, as far as we know, agree that (1b) and (4b) should be derived in the same way. ${ }^{6}$ Together with the fact mentioned above that presuppositions like (2b) and scalar implicatures are considered to be different, we could represent the traditional grouping of these three inferences as in (5).

\section{(5) Traditional grouping}

direct scalar implicatures $=$ indirect scalar implicatures $\neq$ presuppositions

It is clear that the picture in (5) makes two predictions. First, it predicts uniform processing profiles for direct and indirect scalar implicatures. ${ }^{7}$ Second, it predicts their processing and that of presuppositions to be different. In light of what we know from the previous studies on direct scalar implicatures and presuppositions sketched above, we thus expect that the presence of indirect scalar implicatures should be associated with a higher cost than that of their absence, as with direct scalar implicatures, but in contrast with presuppositions. Schematically, these predictions can be illustrated as follows:

\section{(6) Predictions for indirect scalar implicatures:}

a. presence of indirect scalar implicatures $>$ absence of indirect scalar implicatures

b. presence/absence of indirect scalar implicatures $\neq$ presence/absence of presuppositions

\footnotetext{
${ }^{5}$ But see Chemla 2009c for an offline study involving inferences of the type of (4a). For relevant work on the acquisition of indirect scalar implicatures see Musolino and Lidz 2006 and Katsos et al. 2011. Finally, after finishing this paper, the recent manuscript by Cremers and Chemla (2013) came to our attention. We'll have to leave a more detailed comparison with this work to another occasion.

${ }^{6}$ A possible exception is Chierchia 2004, in which direct and indirect scalar implicatures are technically derived in slightly different ways. In this system, however, they are still both scalar implicatures (and different from presuppositions). Therefore, it is not clear that this system has any advantage in accounting for our results below.

${ }^{7}$ A possible complication in this regard involves the presence of negation and its potential processing implications. We will return to this briefly below.
} 
In this paper, we test the predictions in (6) by looking at the processing of indirect scalar implicatures like (4b) in direct comparison with that of presuppositions and against the background of the results in the literature on direct scalar implicatures. As we will see in detail below, the results of our study challenges the prediction for indirect scalar implicatures in (6) (and support the previous finding on presuppositions in (3b)). We find the processing of indirect scalar implicatures to actually be more similar to that of presuppositions than that of direct scalar implicatures. Schematically, the main result of our experiment is represented in (7).

\section{(7) Main results:}

a. presence of indirect scalar implicatures $<$ absence of indirect scalar implicatures

b. presence/absence of indirect scalar implicatures $\approx$ presence/absence of presuppositions

In other words, at least from a processing point of view, the traditional grouping in (5) appears incorrect. In the final part of the paper, we sketch two hypotheses in response to this challenge: the first is that indirect scalar implicatures are actually presuppositions; the second is that they could be scalar implicatures, but of a different kind than direct ones.

The paper is organized as follows: in section (2), we briefly introduce direct and indirect scalar implicatures as well as presuppositions in more detail, and sketch how they are traditionally derived. In section (3) we present our experiment and its results. In section (4), we discuss the implications of the experimental findings and explore two alternative ways of looking at indirect scalar implicatures in theoretical terms in light of our results.

\section{Background}

\subsection{Basic Properties of Implicatures and Presuppositions}

Our example in (1), repeated below, provided a first illustration of direct scalar implicatures. Descriptively speaking, inferences of this sort arise when a weak scalar terms like sometimes appears in an upward entailing context. Further examples are provided in (8) and (9), where the sentences in (8a) and (9a), which contain the scalar terms some and or, respectively, give rise to the implicatures in (8b) and (9b).

(1) a. John sometimes went to the movies.

b. $\hookrightarrow$ John didn't always go

(8) a. Some of the students went to the movies.

b. $\hookrightarrow$ Not all of them went

(9) a. John went to the movies or to the beach. 


\section{b. $\hookrightarrow$ John didn't go both to the movies and to the beach}

Analogously, and in a symmetric fashion, indirect scalar implicatures arise from strong scalar terms embedded in downward entailing environments. We already saw the example in (4); other cases include (10) and (11), where the sentences (10a) and (11a) containing the strong scalar terms all and and give rise to the implicatures in (10b) and (11b).

(4) a. John didn't always go to the movies.

b. $\hookrightarrow$ John sometimes went

(10) a. Not all of the students went to the movies.

b. $\hookrightarrow$ Some of the students did

(11) a. John didn't both go to the movies and to the beach.

b. $\hookrightarrow$ John went to one or the other

One main characteristic of scalar implicatures is that they can easily be suspended. More neutrally, we will say that they appear to be 'absent' in certain cases. For instance, in (12a) and in (12b), the direct scalar implicature that John didn't always go to the movies, for (12a), and the indirect one that John went sometimes to the movies, for (12b), are not present (at least at the end of the continuations which directly contradict them).

a. John sometimes went to the movies... In fact, he always did!

b. John didn't always go to the movies... In fact, he never went!

In brief, direct and indirect scalar implicatures are suspendable inferences of sentences such as (1a) and (4a) and, at least superficially, they are symmetrical and very similar. Indeed, as we will soon see in more detail, they have been treated in a completely unified way. Before sketching the traditional way of deriving these inferences, we turn to presuppositions in a bit more detail.

The example in (2), repeated below, provided a first illustration of a presuppositional inference. Other inferences of this sort include (13b and (14b), which are associated with sentences like (13a) and (14a), containing an it-cleft and an achievement verb like win, respectively.

(2) a. John didn't stop showing up late for class.

b. $\hookrightarrow$ John used to show up late for class

(13) a. It is John who showed up late for class.

b. $\hookrightarrow$ Somebody showed up late for class

(14) a. John didn't win the marathon.

b. $\hookrightarrow$ John participated in the marathon 
The main characteristic property of presuppositions is their behavior in complex sentences (Karttunen, 1973). This is their so-called 'projection' behavior, which can be described as follows: if we consider a sentence like (13a) and we embed it under negation (15a), in the antecedent of a conditional (15b), under a possibility modal $(15 \mathrm{c})$ or in a question (15d), we still draw the inference in (13b). In traditional terminology, the inference in (13b) 'projects' through the embeddings in (15a)-(15d). This projection behavior is generally taken to be a characteristic feature of presuppositions and it is used as a diagnostic for presuppositionality (Chierchia and McConnell-Ginet, 1990; Beaver, 2001).

(15) a. It isn't John who showed up late for class

b. If it is John who showed up late for class, he should apologize.

c. It's possible that it is John who showed up late for class

d. Is it John who showed up late for class?

Similarly to scalar implicatures, we can easily construct cases in which presuppositions appear to be suspended, or 'absent,' in the terminology we used above. In (16), at least after hearing the continuation, we certainly do not conclude that the presuppositional inference that John used to show up late for class is true.

(16) John didn't stop showing up late...

because he never did!

As noticed above, this is not a property of all types of inferences. Compare, for instance, the behavior of entailments, as exemplified by (17): the attempt of suspending/contradicting the inference that John sometimes went to the movies, in parallel to what was done above, sounds contradictory.

(17) John sometimes went to the movies last week... \#In fact he never went!

Summing up, presuppositions are inferences of sentences like (12a) that are not strictly speaking obligatory, and which display a characteristic projection behavior in complex sentences. The theoretical goals of a theory of presuppositions and of scalar implicatures is to explain how these inferences arise and to predict precisely in what circumstances they are arise. In the next section, we turn to sketch the traditional ways in which this is done.

\subsubsection{Traditional Derivation of Implicatures and Presuppositions}

In light of the theoretical goals just stated, we now proceed to briefly sketch what could be described as the 'traditional' take on each of these inferences. This will be a highly simplified and somewhat idealized description, not the least because many of the theories that our description loosely encompasses are very different from each other. Nonetheless, it will suffice for our purpose of illustrating something like the standard theoretical treatment of these inferences. 
Starting with scalar implicatures, we can simply use an idealized Gricean algorithm, as represented in (18) (Grice, 1975). As (18) indicates, the basic idea is that when we hear an utterance, we reason about what the speaker might have said instead (among a restricted set of competitors). We then conclude that some of these competitors are false. More precisely, the competitors that we deem false are those that are stronger than the speaker's utterance.
a. The speaker said A.
b. The speaker might have said B.
c. It's false that B.

One question that arises at this point is how to determine competitors - that is how do we determine B in (18). A simple response is the following: certain words or morphemes, sometimes called 'scalar terms,' are associated with others in the lexicon. For example, sometimes is associated with always, some with all, and or with and. ${ }^{8}$ When we have a sentence containing one or more scalar terms, we can obtain sentential alternatives by replacing the scalar terms in question with their associates. For instance, if the assertion is (19a), we can obtain its sentential competitor in (19b) by replacing sometimes with always. Once we have (19b), we can apply our algorithm in (18) and derive the inference in (20).

(19) a. John sometimes went to the movies.

b. John always went to the movies.

(20) John didn't always go to the movies.

While we are glossing over many details here, what is important for us is that the very same ingredients that we used above for deriving the direct scalar implicature in (20) can automatically account for indirect scalar implicatures like (21b) as well.

(21) a. John didn't always go to the movies.

b. John sometimes went to the movies.

To illustrate, consider the assertion in (21a): we can obtain the competitor in (22) by replacing sometimes with always. ${ }^{9}$ (22) is stronger than the assertion in (21a), and therefore winds up being negated by the algorithm in (18). This yields the inference that it's not true that John didn't sometimes go to the movies, which is equivalent to (21b).

(22) John didn't sometimes went to the movies.

\footnotetext{
${ }^{8}$ See Horn 1972; Rooth 1992; Sauerland 2004 among many others. For a more articulate theory of alternatives see Katzir 2007; Fox and Katzir 2011.

${ }^{9}$ Notice that the positive polarity nature of sometimes makes (22), if asserted, marginal if not completely infelicitous in its interpretation in which sometimes takes narrow scope with respect to negation. As it is generally implicitly done in the literature, we will assume that this is not a feature that applies to alternatives.
} 
In sum, on the traditional view - and essentially in all theories of scalar implicatures that we are aware of - direct and indirect scalar implicatures are derived in the very same way. Before discussing how presuppositions are derived, let us sketch how cases where the implicature winds up being absent can be derived, e.g., in cases like (12a) and (12b), repeated from above.

(12a) John sometimes went to the movies... In fact, he always went!

(12b) John didn't always go to the movies... In fact, he never went!

As already mentioned, on the traditional view implicatures arise as reasoning about what the speaker could have said instead of what she actually said. This perspective can, therefore, easily account for the absence of scalar implicatures. This is because if the speaker makes it clear, as in the continuation in (12a) and (12b) above, that the competitor is true, then as hearers we will obviously not reason that she must think it to be false. ${ }^{10}$

Turning our attention to the derivation of presuppositions, there are many different proposals in the literature on how to derive them, just as with in the case of scalar implicatures. One approach, stemming from work by Stalnaker $(1974,1978)$, Karttunen (1974), and Heim (1983), is to consider presuppositions as definedness conditions on the 'update' of the context by the information associated with the assertion. So for instance, a sentence like (23) can only update a context that already entails the information that John used to show up late for class. If the context doesn't entail this information, either the sentence sounds infelicitous, or this information is understood as an inference of the sentence. ${ }^{11}$

(23) John stopped showing up late for class.

Beyond basic cases such as (23), a theory of presuppositions needs to explain the behavior of presuppositions in complex sentences as well. In the approach above, in particular in Heim 1983, this is done by redefining the semantics of connectives and quantifiers in such a way as to derive the projection properties of presuppositions. In particular, this is done by identifying the meanings of sentences with the ways in which they change the contexts they update (also called 'context change potentials'). Given its identification of the meanings of sentences with the way they change the context they occur in, this approach is called 'dynamic.' It can be shown that this way of proceeding ensures that not only is (23) predicted to presuppose that John used to show up late for class, but also (24a)-(24d) are.

(24) a. John didn't stop showing up late for class.

\footnotetext{
${ }^{10}$ In other cases, other considerations enter into the picture, in particular a notion of 'relevance' is used, so that if it is clear in the context that the competitor would have not been relevant for the goals of the conversation, the scalar implicature is not derived.

${ }^{11}$ In this perspective, the presupposition is said to be 'accommodated' in the context (Lewis, 1979); see von Fintel 2008; Beaver and Zeevat 2012 and references therein for further discussion.
} 
b. If John stopped showing up late for class, Mary will be pleased.

c. It's possible that John stopped showing up late for class

d. Did John stop showing up late for class?

Many other theories of presuppositions have been proposed as well, of course, from partial or trivalent logics to DRT-style approaches Kamp (1981), to more recent pragmatic accounts (for a recent overview, see Schlenker, 2008). But what is most important for our purposes is that these mechanisms are all different from those assumed for deriving scalar implicatures.

As discussed in section 2.1, both implicature- and presupposition-based inferences can be absent in certain circumstances. Given the different theoretical perspectives on the two types of inferences, the absence of presuppositions in cases like (25) is generally derived in a way that's very different from the way absent inferences are derived in the case of scalar implicatures. Theoretically speaking, presuppositions are generally seen as non-negotiable inferences (at least within the accounts we're considering here), and thus always have to be taken into account. How can this, then, be reconciled with their apparent absence in cases like (25)? The key idea is that presuppositions can be interpreted at different levels: when they are computed globally, we expect an inference, but we do not if they are computed in more local positions.

(25) John didn't stop showing up late for class ...

because he never did!

For instance, imagine - for the sake of presentation - that your favorite theory of presuppositions is a function PS, which, given sentences of any complexity, returns their presuppositions: for any $p, \mathbf{P S}(p)=p$ and $p$ 's presuppositions. Imagine also that PS can recursively be applied at any scope site of a sentence. For instance, for a sentence like (26), repeated from above, we have two possible scope sites at which PS could apply. First, it could apply at a global level, as in (27a) and this would give rise to the inference that John used to show up late for class. Second, however, it could also apply vacuously at a local level below negation, as in (27b). This latter option is what corresponds to the 'suspension' or the 'absence' of presuppositions in the traditional view, as this gives rise to an interpretation that is compatible with John never having showed up late for class.

(26) John didn't stop showing up late for class.

a. PS[not[John stopped showing up late for class]]

b. not[PS[John stopped showing up late for class]]

In a case like (25), given that the continuation is incompatible with the global derivation of the presupposition, it is assumed that the presupposition is instead derived locally, as in (27b). In other words, in this approach the presence vs. absence of presuppositions lines up with their global vs. local derivation.

This concludes our rough sketch of possible derivations of scalar implicatures and presuppositions, as well as of accounts of cases where the respective inferences 
are absent. While there are many different alternative implementations, what is most relevant here is that the on essentially all accounts, the stories are quite different for implicatures and presuppositions. In the next section, we turn to a brief summary of what has emerged from studies on the processing of direct scalar implicatures and presuppositions in the literature and their implications for an investigation of indirect scalar implicatures.

\subsection{Processing Implicatures and Presuppositions}

Among the three inferences that we are looking at in this paper, direct scalar implicatures are the ones that have been studied most extensively in the psycholinguistic literature (Bott and Noveck, 2004; Bott et al., 2012; Breheny et al., 2006; Huang and Snedeker, 2009; Chemla and Bott, 2013). A central result that has emerged from these studies is that the processing of direct scalar implicatures appears to be costly. More precisely, evaluating a sentence in a situation consistent with its direct scalar implicature appears to be associated with a higher processing cost than evaluating it in a situation incompatible with its direct scalar implicature (Bott and Noveck 2004; Breheny et al. 2006; Huang and Snedeker 2009; but see Grodner et al. 2010). More specifically, in reaction times studies, the reaction time associated with evaluating a sentence in a situation compatible with its scalar implicature was consistently longer than evaluating it in a situation only compatible with its literal meaning. We can summarize this result as in (28) (Bott and Noveck 2004 among others).

\section{(28) Result on direct scalar implicatures}

presence of direct scalar implicatures $>$ absence of direct scalar implicature

The processing of presuppositions has been studied less than direct scalar implicatures, but the number of studies investigating it has been growing recently (Chemla and Bott 2013; Schwarz 2007; Schwarz and Tiemann 2012, 2013). One common result that has emerged from these recent studies is that, contrary to direct scalar implicatures, it is the absence of presuppositions that gives rise to a higher processing cost. In other words, evaluating a sentence in a situation compatible with its presupposition is associated with a longer reaction time than evaluating it in a situation incompatible with its presupposition. ${ }^{12}$ We can formulate this result as in (29).

\section{(29) Result on presuppositions}

presence of presupposition $<$ absence of presuppositions

As already mentioned, the processing of indirect scalar implicatures has not been investigated in the literature. Given what we know from the studies just described

\footnotetext{
12 Notice that this does not mean that presuppositions per se are not associated with a cost. See Schwarz and Tiemann 2013 for discussion and relevant results on the processing of presupposition projection.
} 
and the unified treatment of direct and indirect scalar implicatures sketched above and repeated in (30), we expect indirect scalar implicatures to behave like direct ones in terms of processing. In other words, everything being equal we expect that evaluating a sentence in a situation consistent with its indirect scalar implicature should be slower than evaluating it in a situation which is inconsistent with its indirect scalar implicature, (31).

(30) Traditional grouping:

direct scalar implicatures $=$ indirect scalar implicatures $\neq$ Presuppositions

(31) Prediction for Indirect scalar implicatures

Presence of indirect scalar implicatures $>$ absence of indirect scalar implicatures

In the next section, we report on an experiment in which we tested the prediction in (31). In particular, we tested (31) in direct comparison to the case of presuppositions and against the background of the results in the literature about direct scalar implicatures.

\section{Experiment: stop vs. not always in the Covered Box paradigm}

In our experiment, we compared indirect scalar implicatures to presuppositions by testing for the availability of different interpretations for strong scalar items and presupposition triggers under negation using the covered box paradigm. This paradigm is particularly well-suited for investigating the existence of non-dominant interpretations and has already been fruitfully utilized in the study of implicatures (Huang et al., 2013) and presuppositions in conditionals (Romoli et al., 2011). It is a variant of a picture-matching task, where participants have to judge the fit of a picture with a given linguistic stimulus. The covered box version adds a layer to the ask by including a (representation of) a covered box, which participants are told hides another picture. In our variant, they are also told that only one of the pictures matches the sentence. If they find none of the overtly shown pictures to match the sentence, the match must be the hidden one and they should select the covered box. The methodology is particularly useful for testing for the availability of non-dominant interpretations, because participants are forced to consider whether an overtly shown picture matching such an interpretation could possibly be seen as corresponding to any available interpretation of the sentence in question. If they choose the covered box instead, this is a clear indication that the relevant interpretation is not available to them. Dominant interpretations can be included as well, of course, and we also included controls to ensure that participants did indeed understand the task and choose the covered box in cases where none of the overt pictures matched any interpretation of the presented sentence.

Our implementation of this paradigm compared cases corresponding to overall interpretations that either did or did not include an inference of interest. In the case 
of indirect scalar implicatures, this was the inference that some activity took place some of the time when the sentence said that it did not always take place. In the case of presuppositions, it was the global interpretation of the presupposition of stop under negation that some activity had been going on prior to the time mentioned in the sentence. The comparison cases involved no such inference, i.e., they involved target pictures where the activity did not go on at all (in the case of indirect scalars) or didn't go on prior to the mentioned time (in the case of stop. Illustrations of the actual stimuli used are introduced in the following subsection.

Based on the traditional picture sketched above, which assumes that indirect scalar implicatures are equivalent to direct scalar implicatures in both their derivation and in processing, we'd expect response behavior results parallel to the wellstudied case of the latter. In particular, we'd expect that the generation of the scalar inference comes with a processing cost that is reflected in an increase in (when comparing trials where the inference is drawn to ones where it is not), and possibly also affects the frequency with which it is chosen as a match. With presuppositions, we expect a different outcome, both based on the standard assumption in the theoretical literature that global interpretations of presuppositions are the default and the initial processing results by Chemla and Bott (2013), where global interpretations are argued to be faster than local ones. Based on these expectations, we thus predict a cross-over interaction, with slower for inference trials with always and faster ones for inference trials with stop.

\subsection{Materials \& Design}

Our materials utilized pictures depicting individuals together with a 5-day calendar strip that contained icons representing various activities or destinations. Subjects were told that these represented what the individuals did during the past week, and they had to identify which of them match the provided linguistic description (see below for procedural details). The critical manipulation varied whether the target picture corresponded to an interpretation that included the inference of interest or not. Illustrations are provided in (32):

a. Benjamin didn't always go to the movies last week.

$\hookrightarrow$ Benjamin sometimes went to the movies last week

i. Inference

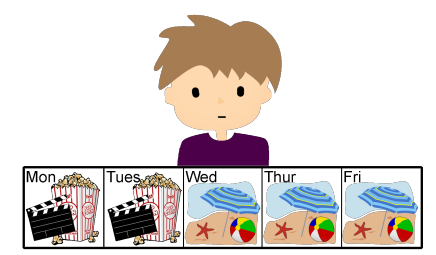

ii. No Inference

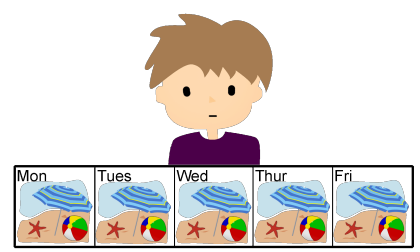


b. Benjamin didn't stop going to the movies on Wednesday

$\hookrightarrow$ Benjamin went to the movies prior to Wednesday

i. Inference

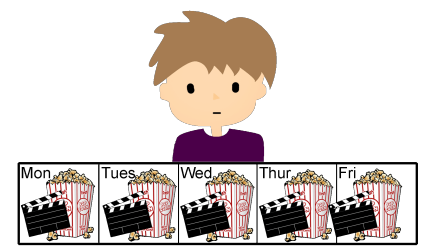

ii. No Inference

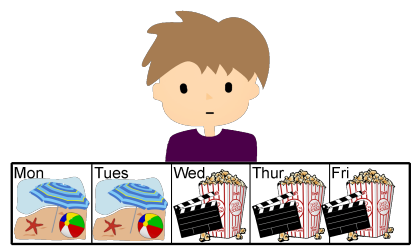

The inference target picture in the always-condition matched the inference at stake for the sentence in (32a), as this person did go to the movies some but not all of the time. The no-inference picture, on the other hand, does not match this inference and thus should only be selected if the inference is not present. Similarly, the inference stop-picture matches the inference in that this person did go to the movies prior to Wednesday (and continued to do so from then on, to match the asserted content as well). But the no-inference picture did not match the inference, as this person did not go to the movies prior to Wednesday. Note that the asserted content - that they did go to the movies from Wednesday on - is still matched by the no-inference picture, so that the participants' decision about whether this picture matches the sentence is a clear indicator of whether or not the inference based on the global presupposition is present or not. Note furthermore that under a local interpretation of the presupposition, this picture does match the sentence, as the negation of the conjunction Benjamin went to the movies before Wednesday and he went to the movies on Wednesday and thereafter is indeed true of it.

In addition to the target and the covered box, a third distractor item was included as well. Distractors included a picture of another individual and were constructed so as not to match either interpretation of the respective sentences (e.g., the distractor for the always-conditions had a boy that went to the movies every day, and the one for the stop-condition had a boy that went to the beach from Monday through Thursday and to the movies on Friday).

A total of 12 items were created with variants in all four conditions described above. Furthermore, an additional experimental manipulation involving the interpretation of the verb think under negation was included, which we will not discuss here in detail for reasons of space. In brief, a sentence such as Benjamin doesn't think he will go to the movies on Thursday can, but does not necessarily, give rise to the inference that Benjamin is certain that he won't go to the movies on Thursday. We varied pictures here by either including another activity on Thursday or placing a question mark there. Given the future-orientedness of these stimuli, they were presented in a separate block of the experiment where participants were told that 
the calendar strips represented the corresponding individuals' plans for the coming week. Order of blocks was counter-balanced between participants. ${ }^{13}$

In addition to the experimental stimuli, several types of filler items without negation were included. First, there was a set of 12 items with sentences containing stop without negation. For half of these, the target picture matched the sentence, and for the other half it did not and thus required selection of the covered box. Similarly, there were 12 items using always without negation, again split in half with respect to whether or not the target matched the sentence. In the block on think, parallel control variants without negation were included.

\subsection{Procedure \& Participants}

After signing a consent form, participants were seated in front of a computer, where the experimental program prepared in SR Research's Experiment Builder was started. They were then shown instructions that told them that they were taking on the role of a detective in a guessing game, where they would see three pictures, one of them blocked from view, and a sentence, which was a piece of intercepted communication from a suspect about their activities during a certain week. Based on that intercepted information, they were to decide who was the suspect, under the assumption that only one of the three pictures was compatible with the sentence, and that the covered box would therefore need to be chosen if neither one of the overt pictures matched the sentence. The choice was carried out by using a mouse to click on the selected picture. Prior to displaying the images and the sentence, a fixation cross was presented in the center of the screen for $1000 \mathrm{~ms}$.

After the instructions, the first block started with two practice trials to familiarize them with the task. One block consistent of the stop and not always items and fillers, and the other of the think items. Each block had its own practice trials, as they differed in that one was about the past week and the other about the upcoming one.

The expression factor was used as a within subject factor, i.e., participants saw three out of the six variations of each item, one with each expression (stop, not always, think). Whenever they saw the stop version of an item in the inference condition, they saw they always version in the no-inference condition and vice versa. Each subject completed a total of 36 experimental trials, $(24$ and 12 in the respective blocks), as well as 36 filler trials (again 24 and 12 in the different blocks).

25 undergraduate students from the University of Pennsylvania, all native speakers of English, participated in the experiment for course credit. They were randomly assigned to 4 groups for counterbalancing both the inference vs. no-inference conditions and the block order. Each subject saw 6 items in each condition.

\footnotetext{
${ }^{13}$ For those curious about the results, we found no differences between inference and no-inference trials for this sentence type, in contrast with the other two, as discussed below. We have to leave the interpretation of this result for another occasion.
} 


\subsection{Results}

\subsubsection{Data Treatment}

For purposes of analysis, responses were coded with respect to whether participants selected the target picture or the covered box. Trials where the distractor was chosen were considered as errors and were removed (2.5\% of trials fell into this category, leaving 585 out of 600 data points for analysis). Reaction times were calculated as the time that passed from initial display of the images and the sentence until the mouse click occurred.

\subsubsection{Statistical Analysis}

The average proportions of target choices by condition is depicted in Figure 1. As can be seen from the graph, target choices were much less frequent in the No Inference condition, both for stop and always: While the Inference conditions were at ceiling with close to $100 \%$ target choices, there were only around $27 \%$ (always) and $29 \%$ (stop) of trials with target choices. Note that there also was a rather striking divide between participants with slightly over half of them (14) never making any target choices in the No Inference condition, and slightly less then half of them (11) making target choices around two thirds of the time (for both stop and always). Furthermore, inspecting target choices relative to trial order, it appeared to be the case for most of the participants belonging to the latter group that they did not initially select the target on No Inference trials, but then switched and stuck with target choices from then on. There were two participants which only had target choices for stop in the No Inference condition, and one that only had target choices for always in that condition. All others had target choices for both expressions.

Fig. 1 Mean percentages of Target choices proportion by condition

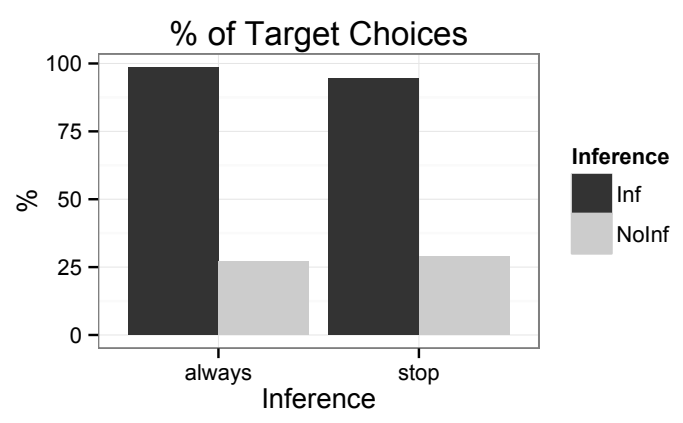

To analyze the pattern in responses statistically, we carried out mixed effect model logistic regression analyses using the lmer package in $R$ (Bates, 2005). While we tried to include random slopes for both factors and their interaction, follow- 
ing the recommendation of Barr et al. (2013), the corresponding models did not converge, and we thus only included random intercepts (for both participants and items). We report estimates, standard errors, $z$-values, and $p$-values from the lmer output. A $2 \times 2$ interaction analysis (stop vs. always and Inference vs. No Inference) using centered factors yielded a main effect of the Inference factor $(\beta=6.73$, $S E=0.62, z=10.8, p<.001)$. There was no main effect of expression and no significant interaction, but the effect of the Inference manipulation was slightly more pronounced in the always conditions in numerical terms. Planned comparisons for the effect of the Inference factor within each type of expression were carried out by using the appropriate treatment coding. There was a simple effect of the Inference factor for both stop $(\beta=5.90, S E=0.61, z=9.66, p<.001)$ and always $(\beta=7.53$, $S E=0.95, z=7.91, p<.001){ }^{14}$

In summary, targets were selected much less frequently in the No Inference condition. For the indirect scalar implicature with not always, this is somewhat surprising given previous results for direct implicatures. Using essentially the same task, involving picture selection with a covered box, Huang et al. (2013) found $87 \%$ target choices in the equivalent of a No Inference $(\approx$ literal) condition with the quantifier some. Furthermore, several studies conducted in our lab using a truth-value judgment task rendered similarly high acceptance rates in (the equivalent of) No Inference conditions. For presuppositions, there is much less precedent, though Chemla and Bott (2013) found about 50\% of (the equivalent of) No Inference responses in a truth-value judgment task with factive verbs such as realize and know. Looking at both expressions together, what stands out that they seem to behave quite similarly as far as participants' response behavior is concerned, even though we traditionally would not group them together, as discussed above.

Turning to reaction times, we again find similar patterns of results for the two expressions we investigated. The mean for target choices in the Inference and No Inference conditions are graphed in Figure 2. For both always and stop, target choices in the No Inference conditions were slower than in the Inference conditions. To evaluate these differences statistically, we ran mixed effect model analyses, again using the lmer function in $R$. Statistical analyses used mixed-effect models with participants and items as random effects, using the lmer function of the lme4 package in $R$ Bates (2005). Following Barr et al. (2013), the maximal random effect structure that was suitable for the design and that would converge was used, with a random intercept as well as random slopes. To assess whether inclusion of a given factor significantly improved the fit of the overall model, likelihood-ratio tests were performed that compared two minimally different models, one with the fixed effects factor in question and one without, while keeping the random effects structure identical (Barr et al., 2013). We report estimates, standard errors, and $t$-values for all models, as well as the $\chi^{2}$ and $p$-value from the likelihood-ratio test for individual factors.

A $2 \times 2$ interaction analysis, with random intercepts and random slopes for type of expression for participants and items and a random slope for the Inference fac-

14 These effects were also present when looking only at data from the participants with target choices in the No Inference condition. 
Fig. 2 Mean for Target

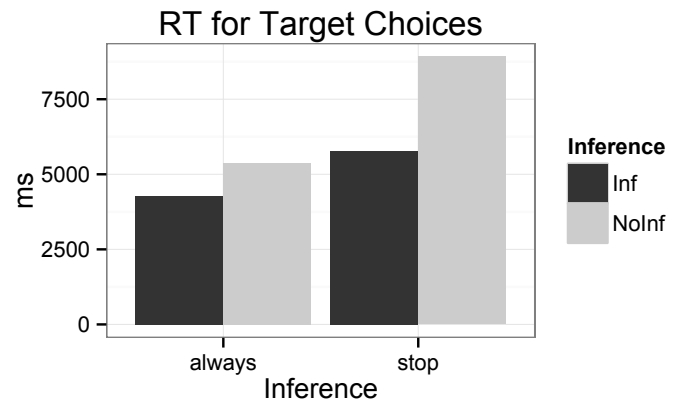
choices by condition

tor for items, yielded significant a main effect of Inference $(\beta=1517, S E=437$, $\left.t=3.47 ; \chi^{2}=7.73, p<.01\right)$, with slower in the No Inference condition. There also was a main effect of expression (RES-2124: $\beta=558, S E=3.81, t=11.40$; $\chi^{2}=.001, p<$,) with slower for stop, but no significant interaction. The main effect of expression includes reading times for the sentence, and thus may at least in part be due to differences in sentence structure. Planned comparisons between the Inference and No Inference conditions for stop and always suggest that the difference is present for both expressions, reaching significance for stop $(\beta=2110, S E=619$, $\left.t=3.41 ; \chi^{2}=4.16, p<.05\right)$, and approaching it for always $(\beta=948, S E=618$, $\left.t=1.53 ; \chi^{2}=2.37, p<.13\right){ }^{15}$ Taken together, the upshot of the reaction time results is that target choices in the No Inference condition are slower than in the Inference condition.

Given the split in participants with respect to whether or not they had any target choices in the No Inference condition at all, we conducted some post-hoc analyses as well to further investigate differences between these groups. The No Inference participants seemed to exhibit slower overall. Comparing for covered box choices in the local conditions revealed a significant difference between them and the group without any target choices in the No Inference condition $(\beta=4365, S E=1637$, $\left.t=2.67 ; \chi^{2}=6.70, p<.01\right)$. Similarly, target choices in the global conditions were marginally slower for them as well (RES-1162: $\beta=659, S E=1.76, t=3.09$; $\left.\chi^{2}=.1, p<.\right)$

There are some interesting methodological points to note as well, concerning the use of the covered box design for investigating response times. Note that the central comparisons of interest above are all comparisons between equivalent choices, all involving trials where the target picture was chosen. This allows for a more straightforward comparison between different interpretations, as it avoids issues such as the well-known response bias effect, which commonly yields slower response times for false answers in truth-value judgment tasks. Interestingly, covered box choices were not significantly slower than target choices (looking at the local conditions for the

${ }^{15}$ As with the response data, largely parallel results are also obtained when just looking at the data from participants with target choices in the No Inference condition. 
No Inference participants). Another interesting point to note in this regard is that comparing target vs. covered box choices for the No Inference participants yields a rather different pattern from the results discussed above. While the No Inference responses were slower than the Inference responses, rejections of the target picture in the No Inference conditions was even slower than their acceptance (though only numerically). A result along these lines alone might have suggested a very different line of interpretation, though it might face some of the same issues as existing reaction time studies (e.g., with respect to response bias). Of further interest is the fact that covered box choices of those participants that never had any target choices in the No Inference condition were (numerically) faster even than the target choices of the participants from the other group. While we cannot pursue these issues in further detail here for reasons of space, these methodological points seem well worth investigating in greater depth, and we are currently extending the paradigm to direct scalar implicatures as well.

\section{Discussion}

We saw above how direct and indirect scalar implicatures are typically considered part of the same phenomenon and different from presuppositions. Our results challenge this standard picture. In particular, we found that the proportion of No inference choices with the strong scalar term always was much lower than in other studies investigating direct scalar implicatures as arising from weak scalar terms like some (Huang et al. 2013 in particular). More importantly, the reaction time associated with the No inference choice was slower than that associated with the Inference choice, not only with stop but also with always, in contrast with findings in the literature for direct scalar implicatures. The result for stop is consistent with previous findings (Chemla and Bott, 2013), while that associated with always is a novel result. The most informative part of the results, however, is the direct comparison between the two inferences.

To illustrate the implication of our results more schematically, recall that the traditional grouping of these inferences is that sketched in (5). Given what we know about the processing of direct scalar implicatures and that of presuppositions, the prediction of the traditional approach was that the presence of indirect scalar implicatures should give rise to a longer response time than its absence.

\section{(5) Traditional grouping}

direct scalar implicatures $=$ indirect scalar implicatures $\neq$ presuppositions

(6) Predictions for indirect scalar implicatures:

a. presence of indirect scalar implicatures

$>$ absence of indirect scalar implicatures

b. presence/absence of indirect scalar implicatures

$\neq$ presence/absence of presuppositions 
Our results thus do not support the prediction in (6): the processing of indirect scalar implicatures appears more similar to that of presuppositions than that of direct scalar implicatures. In other words, the reaction time associated with the presence of indirect scalar implicatures was shorter than that associated with their absence.

\section{(7) Main results:}

a. presence of indirect scalar implicatures $<$ absence of indirect scalar implicatures

b. presence/absence of indirect scalar implicatures $\approx$ presence/absence of presuppositions

The outcome in (7) is a challenge for the traditional view, and in the next section we briefly consider two responses that we are exploring in light of this challenge. Before doing so, let us briefly touch on two relevant points. First, let us emphasize that at this point we did not test direct scalar implicatures in our design. Therefore our discussion below relies on previous results in the literature. While the methodologies of other response time studies are comparable to ours, we are currently in the process of testing direct scalar implicatures in a within-subject experiment with direct ones. Until then, our discussion relies on the assumption that direct scalar implicatures will give rise to a delay in the same way they did in previous studies. Secondly, we want to discuss the relevance of our results for some more recent accounts of presuppositions that treat them more like indirect scalar implicatures (Chemla 2009a; Romoli 2012, Romoli (to appear); see also Simons 2001; Abusch 2010). In these approaches, (at least some) presuppositions are essentially considered to be indirect scalar implicatures. This can in principle account very well for the similarity in processing that we found. However, there are two issues that are also not straightforwardly solved in these approaches. First, as we will see below, there are other differences between indirect scalar implicatures and presuppositions that need to be accounted for. Once these differences are explained in these recent approaches, however, it is not clear that the similarity in processing is still expected. ${ }^{16}$ Secondly, these accounts still propose that direct and indirect scalar implicatures should be handled in a unified way and this appears problematic given our results.

In sum, the results presented above are challenging for a traditional view of indirect scalar implicatures, and they are also not straightforwardly accounted for in more recent approaches treating presuppositions and indirect scalar implicatures in a more or less parallel way. In the next section, we turn to two hypotheses in response to this challenge.

\footnotetext{
${ }^{16}$ For instance, Romoli (2012), Romoli (to appear) proposes that some presuppositions are obligatory indirect scalar implicatures and this can account for certain differences with 'regular' indirect scalar implicatures. But then, once we distinguish between presuppositions and indirect scalar implicatures in this way, it is not clear anymore that the similarity in processing is expected.
} 


\subsection{Presuppositions or Obligatory Implicatures?}

Our results challenge the idea that indirect scalar implicatures are simply regular scalar implicatures, because they appear to have different processing profiles. What could indirect scalar implicature be then if not simply regular scalar implicatures? We explore two hypotheses. First, we focus on the idea that indirect scalar implicatures could actually be presuppositions. ${ }^{17}$ Second, we consider a different option, one that takes indirect scalar implicatures to be a different type of scalar implicature.

\subsubsection{Indirect scalar implicatures as presuppositions}

The first hypothesis could be formulated as in (33). According to (33), a sentence like (34a) not only entails but also presupposes, in the traditional sense, its sentential alternative (34b).

(33) Indirect scalar implicatures as presuppositions: strong scalar terms presuppose their weakest competitor. ${ }^{18}$

(34) a. John always went to the movies.

b. John sometimes went to the movies.

Now, of course, if (34a) presupposes (34b), it follows from any mechanism for deriving presupposition projection, that (34b) is also a presupposition of (35).

(35) John didn't always go to the movies.

Moreover, if (34b) is a presuppositions of sentences like (34a) or (35), then it is indeed expected that its processing should be similar to that of presuppositions such as that associated with stop. The hypothesis in (33) can, therefore, account for our processing results.

There are, however, several issues with the hypothesis in (33) that remain open at this point. These issues are related to (at least potential) differences between presuppositions and indirect scalar implicatures. In particular, in relation to the projection behavior of presuppositions, e.g., in the context of connectives, modals and questions, as well as to the persistence of the projection of the inference in quantificational environments.

Starting with the first point concerning connectives, modals, and questions, we saw above that we want our theory of presuppositions to predict that all of (36a)(36e) should give rise to the inference that somebody showed up late for class.

(36) a. It is John who showed up late for class

\footnotetext{
17 Thanks to Danny Fox (p.c.) for suggesting this way of looking at indirect scalar implicatures.

${ }^{18} \mathrm{We}$ only consider here the weakest competitor as a presupposition. This immediately raises the question as to whether also other intermediate members of the scale, like 'often' in this case, should be considered presuppositions. We leave this issue for future research.
} 
b. It isn't John who showed up late for class

c. It's possible that it is John who showed up late for class

d. Is it John who showed up late for class?

e. If it is John who showed up late for class, he should apologize.

If indirect scalar implicatures are presuppositions, we expect the same projection behavior. In other words, we expect all of (37a)-(37e) to presuppose that John sometimes went to the movies.

(37) a. John always went to the movies.

b. John didn't always go to the movies.

c. It's possible that John always went to the movies.

d. Did John always go to the movie?

e. If John always went to the movies, he will be able to suggest a good movie.

Based on our own intuitions, it is not clear that the inference that John sometimes went to the movies from (37b)-(37e) is as robust as the one that someone showed up late for class arising from (36b) to (36e), or even whether it is present at all. Such intuitions are rather subtle, however, so a more systematic investigation is needed to establish this data point.

Another relevant case, investigated by Chemla (2009a), is that of negative quantifiers like (38a) and (39a). When presented with a sentence like (38a) and asked whether the universal inference in (38c) followed, the participants of the experiments by Chemla (2009a) were largely willing to give an affirmative answer.

(38) a. None of these ten students won the marathon.

b. Some of these ten students participated in the marathon.

c. Each of these ten students participated in the marathon.

More precisely, the inference in $(38 \mathrm{c})$ was accepted more often $(\approx 80 \%)$ than the analogous universal inference with a scalar implicature in $(39 c)$ from $(39 a)(\approx$ $25 \%$ ).

(39) a. None of my professors failed all of their students.

b. Some of my professors failed some of their students.

c. All of my professors failed some of their students.

This result tells us that in the scope of negative quantifiers there is a difference in the degree to which presuppositional triggers and strong scalar terms give rise to universal inferences. ${ }^{19}$ And this difference is unexpected based on the hypothesis in (33) above, which treats indirect scalar implicatures and presuppositions uniformly.

\footnotetext{
${ }^{19}$ Notice that, importantly, these results by no means imply that sentences like (39a) do not give rise at all to universal inferences like that in (39c). See Romoli 2012, Romoli (to appear) for arguments in favor of the existence of tg inference.
} 
Finally, the hypothesis in (33) does not say anything about whether the inferences that we have labeled indirect scalar implicatures arise only because they are presuppositions, or whether the same inference is additionally supported by standard implicature reasoning. In fact, for most theories of scalar implicatures, it seems hard to even block deriving them as scalar implicatures as well, based on an account of direct ones in terms of reasoning about scalar alternatives in terms of logical strength. If indirect scalar implicatures are derived both based on scalar reasoning and because they are presupposed, this raises obvious questions about how these two components interact. We have to leave the exploration of these open issues for a future occasion.

\subsubsection{Indirect scalar implicatures as obligatory scalar implicatures}

Another idea possibility to explore in order to account for our results is that indirect scalar implicatures could be a type of scalar implicatures distinct from direct ones, with corresponding differences in their processing properties. In particular, we focus on the notion of 'obligatory' scalar implicatures, recently proposed by Spector 2007; Chierchia et al. 2012. This second hypothesis can be formulated as in (40).

(40) Indirect scalar implicatures as obligatory scalar implicatures: Indirect scalar implicatures are obligatory.

The obligatoriness in (40) can be implemented in different ways and we will remain neutral on how this should be done. What is relevant for us is that if indirect scalar implicatures are obligatory scalar implicatures, we can account for our results about their processing in the following way. First, consider how we would explain cases in which indirect scalar implicatures are absent in this approach. This is not straightforward, because if they are obligatory, we cannot simply say that they are not derived in the first place, based on contextual information about the speaker's beliefs. However, in the same way as what we described is standardly done for presuppositions, we can resort to a local derivation of scalar implicatures. To illustrate, imagine your theory of scalar implicatures to be a function SI, which applied to a sentence returns its meaning strengthened with a scalar implicature. For instance, for any $p, \mathbf{S I}(p)=p$ and $p$ 's scalar implicatures. Moreover, imagine that SI can be recursively applied at any scope site of a complex sentence. If you have a sentence like (41), repeated from above, there are at least two scope sites at which you can apply your SI. First, you can apply it globally, as in (42a), which gives rise to the indirect scalar implicature that John sometimes went to the movies. Second, however, you could apply it locally, under the scope negation (42b). This local derivation is vacuous, therefore this is equivalent to the absence of the indirect scalar implicatures (i.e., in this interpretation, (41) is compatible with a situation in which John never went to the movies).

(41) John didn't always go to the movies.

a. SI[not[John always went to the movies]] 
b. not[SI[John always went to the movies]]

In sum, if we take this approach, we can account for the cases in which indirect scalar implicatures are suspended as cases of (vacuous) local scalar implicatures. Having local interpretations available is useful independently. We know from the literature that the distribution of scalar implicatures generally appears to be sensitive to the polarity of the context in which the scalar term is embedded. In other words, scalar implicatures tend not to arise when the corresponding scalar term is embedded in downward entailing contexts. ${ }^{20}$ However, it is possible to force the strengthened interpretation of a scalar term in a downward entailing context, though such an interpretation appears to be marked. For instance, one way to account for how (44) is compatible with its continuation is to assume that it should be interpreted with a local scalar implicature under negation, as in (45). This interpretation could be paraphrased as either John met neither Paul nor Mary or he met both of them and it is, therefore, compatible with the continuation that he met both of them.

(44) John didn't meet Paul or Mary ... he met both of them!

$$
\text { not[SI[John met Paul or Mary]] }
$$

Now, if we make the plausible assumption that the intuitive markedness of local scalar implicatures in downward entailing contexts is reflected in processing and assume that our No Inference condition involves precisely that, we can account for the processing cost associated with that condition. This is because, on this approach, the only way the participants of our experiment could chose a picture incompatible with the indirect scalar implicature for a case like (46) is if they computed it locally under negation. The observed markedness plausibly can be seen as corresponding to the observed delay in processing.

\section{John didn't always go to the movies.}

In light of the differences between indirect scalar implicatures and presuppositions discussed above, which are potentially problematic for an account of the former in terms of the latter, it is worth considering how the present hypothesis fares in this regard. Given that this hypothesis does not assume that indirect scalar implicatures are presuppositions, it could, in principle, explain the differences with presuppositions better. To illustrate, consider first the case of connectives, modals, and questions. Here we do not predict the same projection pattern for both types of

${ }^{20}$ To illustrate, consider the following minimal pair from Chierchia (in press): while (43a) is easily interpreted with an exclusive reading of disjunction (i.e., everyone likes Mary or Sue but not both), this is not the case for (43b). In other words, (43b) is generally interpreted as not suggesting that if someone likes both Mary and Sue, she won't write to the dean (see Panizza et al. 2009 for discussion and experimental data that show the sensitivity of scalar implicatures to polarity).

(43) a. Everyone either likes Mary or likes Sue and will write to the dean.

b. Everyone who either likes Mary or likes Sue will write to the dean. 
inferences..$^{21}$ For illustration, take the case of possibility modals and the antecedent of conditionals. In the former case, the alternative that we obtain in (47b) for (47a) is entailed by the assertion so no inference is predicted - specifically the inference that John sometimes went to the movies is not predicted.
a. It's possible that John always went to the movies.
b. It's possible that John sometimes went to the movies.

Similarly, in the case of antecedents of conditionals, the alternative that we have for (48a) is (48b), which is stronger than the assertion, so it winds up being negated. The inference that we obtain, however - it's false that if John sometimes went to the movies, he skipped the cooking classes - is not the projection-like inference that a theory of presuppositions would obtain (namely that John sometimes went to the movies).

(48) a. If John always went to the movies, he skipped the cooking classes.

b. If John sometimes went to the movies, he skipped the cooking classes.

As far as the difference between universal and negative quantifiers in (49b) and (50b) is concerned, while (50b) might as well be an inference of (50a), given that in this approach presuppositions and indirect scalar implicatures are different in nature, it is not expected that the rate of acceptance of (50b) should be the same as that of (49b). ${ }^{22}$ In other words, this approach is compatible with the results by Chemla (2009a).

(49) a. None of these students stopped showing up late for class.

b. All of these students used to show up late for class.

a. None of these students did all of the readings .

b. All of these students did some of the readings.

In sum, we have sketched two alternative theoretical perspectives on indirect scalar implicatures that differentiate them from direct ones, and discussed how this could account for our results. At this point both hypotheses require fleshing out and further exploration, but we have to leave a more detailed investigation for future research. Relatedly, we note that, as part of the general project of comparing direct and indirect scalar implicatures and presuppositions, we are currently investigating the case of always under negation in direct within-participants comparison with that of sometimes in positive sentences. Additionally, we are also in the process of comparing children's knowledge of direct and indirect scalar implicatures, as well as presuppositions, to provide yet another angle on the comparison of these inferences. We hope that taken together, this series of studies will provide the basis for a more comprehensive understanding of the types of inferences discussed here.

${ }^{21}$ We do not predict projection inferences, unless we make additional assumptions. See Chemla 2009a; Romoli 2012, Romoli (to appear) for scalar implicature-based account of presuppositions, which do make additional assumptions for deriving their projection behavior.

${ }^{22}$ See Romoli 2012 Romoli (to appear) for arguments in favor of having the inference in (50b) from (50a) and a proposal on how to derive it as a scalar implicature, 


\section{References}

Abusch, D. (2010). Presupposition triggering from alternatives. Journal of Semantics 27(1), $37-80$.

Barr, D. J., R. Levy, C. Scheepers, and H. J. Tily (2013). Random effects structure for confirmatory hypothesis testing: Keep it maximal. Journal of Memory and Language 68(3), 255-278.

Bates, D. M. (2005). Fitting linear mixed models in r. R News 5, 27-30.

Beaver, D. (2001). Presupposition and Assertion in Dynamic Semantics. Stanford, CA: CSLI Publications.

Beaver, D. and B. Geurts (2012). Presuppositions. In C. Maienborn, K. von Heusinger, and P. Portner (Eds.), Semantics: An International Handbook of Natural Language Meaning volume 3. Berlin: Mouton de Gruyter.

Beaver, D. and H. Zeevat (2012). Accommodation. In G. Ramchand and C. Reiss (Eds.), Oxford Handbook of Linguistic Interfaces. Oxford University Press.

Bott, L., T. M. Bailey, and D. Grodner (2012). Distinguishing speed from accuracy in scalar implicatures. Journal of Memory and Language 66(1), 123-142.

Bott, L. and I. A. Noveck (2004). Some utterances are underinformative: The onset and time course of scalar inferences. Journal of memory and language 51(3), 437-457.

Breheny, R., N. Katsos, and J. Williams (2006, July). Are generalised scalar implicatures generated by default? an on-line investigation into the role of context in generating pragmatic inferences. Cognition 100(3), 434-463.

Chemla, E. (2009a). Presuppositions of quantified sentences: experimental data. Natural Language Semantics 17(4), 299-340.

Chemla, E. (2009b). Similarity: Towards a unified account of scalar implicatures, free choice permission and presupposition projection. Under revision for Semantics and Pragmatics.

Chemla, E. (2009c). Universal implicatures and free choice effects: Experimental data. Semantics and Pragmatics 2(2), 1-33.

Chemla, E. and L. Bott (2013). Processing presuppositions: Dynamic semantics vs pragmatic enrichment. Language and Cognitive Processes 38(3), 241-260.

Chemla, E. and L. Bott (under review). Processing inferences at the semantics/pragmatics frontier: disjunctions and free choice. Ms Ecole Normal Superieure.

Chierchia, G. (2004). Scalar implicatures, polarity phenomena and the syntax/pragmatics interface. In A. B. (ed) (Ed.), Structures and Beyond. Oxford University Press.

Chierchia, G. (in press). Logic in Grammar: Polarity, Free Choice, and Intervention. Oxford University Press.

Chierchia, G., D. Fox, and B. Spector (2012). The grammatical view of scalar implicatures and the relationship between semantics and pragmatics. In C. Maienborn, K. von Heusinger, and P. Portner (Eds.), Semantics: An International Handbook of Natural Language Meaning volume 3. Berlin: Mouton de Gruyter. 
Chierchia, G. and S. McConnell-Ginet (1990). Meaning and Grammar. An Introduction to Semantics. Cambridge, MA: MIT Press.

Cremers, A. and E. Chemla (2013). Direct and indiretc scalar implicatures share the same processing signature. Ms., Ecole Normal Superieure, Paris.

von Fintel, K. (2008). What is presupposition accommodation, again? Philosophical Perspectives 22(1), 137-170.

Fox, D. and R. Katzir (2011). On the characterization of alternatives. Natural Language Semantics 19(1), 87-107.

Geurts, B. (2010). Quantity Implicatures. Cambridge University Press.

Grice, H. (1975). Logic and conversation. In P. Cole and J. Morgan (Eds.), Syntax and semantics: Speech acts. New York: Academic Press.

Grodner, D. J., N. M. Klein, K. M. Carbary, and M. K. Tanenhaus (2010). "Some," and possibly all, scalar inferences are not delayed: Evidence for immediate pragmatic enrichment. Cognition 116(1), 42-55.

Heim, I. (1983). On the projection problem for presuppositions. In M. Barlow, D. Flickinger, and M. Wescoat (Eds.), WCCFL 2, pp. 114-125.

Horn, L. (1972). On the Semantic Properties of Logical Operators in English. Ph. D. thesis, UCLA.

Huang, Y., E. Spelke, and J. Snedeker (2013). What exactly do number words mean? Language Learning and Development 9(2), 105-129.

Huang, Y. T. and J. Snedeker (2009). Online interpretation of scalar quantifiers: Insight into the semantics-pragmatics interface. Cognitive psychology 58(3), 376415.

Kamp, H. (1981). A theory of truth and semantic representation. In J. Groenendijk, T. Janssen, and M. Stokhof (Eds.), Formal Methods in the Study of Language: Proceedings of the Third Amsterdam Colloquium, Volume I, Amsterdam, pp. 227-321. Mathematical Center.

Karttunen, L. (1973). Presuppositions of compound sentences. Linguistic Inquiry 4(2), 169-193.

Karttunen, L. (1974). Presupposition and linguistic context. Theoretical Linguistics 1, 181-194.

Katsos, N., C. Andrés Roqueta, R. A. C. Estevan, and C. Cummins (2011). Are children with specific language impairment competent with the pragmatic and logic of quantification? Cognition 119, 43-57.

Katzir, R. (2007). Structurally-defined alternatives. Linguistic and Philosophy 30(6), 669-690.

Lewis, D. (1979). Scorekeeping in a language game. In R. Bäuerle, U. Egli, and A. von Stechow (Eds.), Semantics from Different Points of View. Berlin: Springer.

Musolino, J. and J. Lidz (2006). Why aren't children universally successful with quantification? Linguistics 44(4), 817-852.

Panizza, D., G. Chierchia, and J. Clifton, Charles (2009). On the role of entailment patterns and scalar implicatures in the processing of numerals. Journal of Memory and Language 61(4), 503-518.

Romoli, J. (2012). Soft but Strong: Neg-raising, Soft Triggers, and Exhaustification. $\mathrm{Ph}$. D. thesis, Harvard University. 
Romoli, J. (to appear). The presuppositions of soft triggers are obligatory scalar implicatures. Journal of Semantics.

Romoli, J., Y. Sudo, and J. Snedeker (2011). An experimental investigation of presupposition projection in conditional sentences. Proceedings of SALT 21, 592608.

Rooth, M. (1992). A theory of focus interpretation. Natural Language Semantics 1(1), 117-121.

Sauerland, U. (2004). Scalar implicatures in complex sentences. Linguistics and Philosophy 27(3), 367-391.

Schlenker, P. (2008). Presupposition projection: The new debate. In T. F. 2008 and S. Ito (Eds.), Proceedings of SALT 18, Ithaca, NY. CLC Publications.

Schwarz, F. (2007). Processing presupposed content. Journal of Semantics 24(4), 373-416.

Schwarz, F. and S. Tiemann (2012). Presupposition Processing-The case of german wieder. In M. Aloni, V. Kimmelman, F. Roelofsen, G. Weidman Sassoon, K. Schulz, and M. Westera (Eds.), Proceedings from the 18th Amsterdam Colloquium, FoLLI. Springer.

Schwarz, F. and S. Tiemann (2013). The path of presupposition projection in processing - the case of conditionals. In E. Chemla, V. Homer, and G. Winterstein (Eds.), Proceedings of SuB 17, pp. 509-526.

Simons, M. (2001). On the conversational basis of some presuppositions. In Proceedings of SALT, Volume 11, pp. 431-448.

Spector, B. (2007). Aspects of the pragmatics of plural morphology: On higherorder implicatures. In U. Sauerland and P. Stateva (Eds.), Presupposition and Implicature in Compositional Semantics. Palgrave.

Stalnaker, R. (1974). Pragmatic presuppositions. In M. K. Milton and P. K. Unger (Eds.), Semantics and Philosophy. New York: New York University Press.

Stalnaker, R. (1978). Assertion. In P. Cole (Ed.), Pragmatics, Volume 9 of Syntax and Semantics, pp. 315-322. New York: Academic Press. 